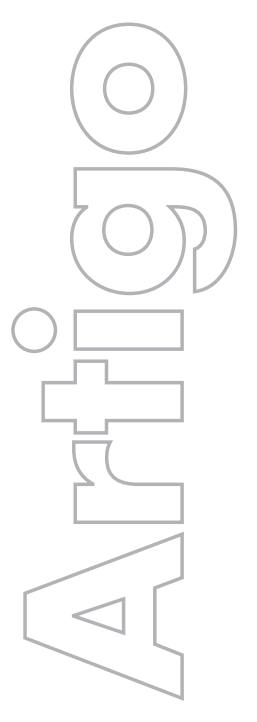

revista

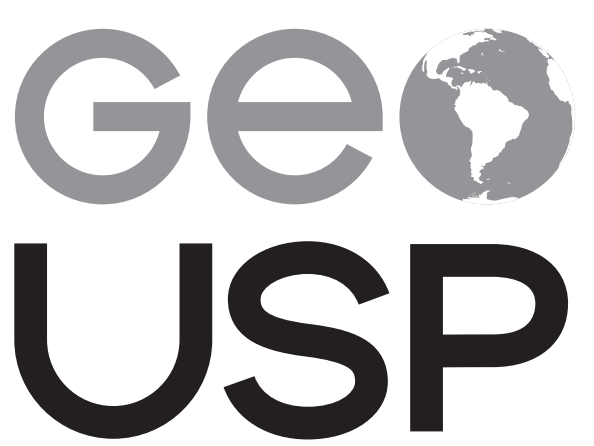

espaço e tempo

Volume $23 \cdot n^{\circ} 2$ (2019)

ISSN 2179-0892

\section{A dinâmica na rede} urbana brasileira atual e a capilarização da informação pelo smartphone no território

\author{
Mait Bertollo \\ Universidade de São Paulo - Brasil
}

p. $262-284$

Como citar este artigo:

BERTOLLO, M. A dinâmica na rede urbana brasileira atual e a capilarização da informação pelo smartphone no território. Geousp - Espaço e Tempo (Online), v. 23, n. 2, p. 262-284, ago. 2019. ISSN 2179-0892.

Disponível em: https://www.revistas.usp.br/geousp/article/ view/156773. doi: https://doi.org/10.11606/issn.2179-0892. geousp.2019.156773.

\section{(c) $(1) \Theta$}

Este artigo está licenciado sob a Creative Commons Attribution 4.0 License. 


\title{
A dinâmica na rede urbana brasileira atual e a capilarização da informação pelo smartphone no território
}

\begin{abstract}
Resumo
A capilarização da informação no território brasileiro por meio do smartphone e suas decorrências espaciais resultam da convergência das técnicas de telefonia e internet, cuja rede expande seu alcance para atender à demanda crescente de conexão, sob a regulação de agentes públicos e privados que determinam a implementação e o uso dessas infraestruturas. $\bigcirc$ principal suporte do ordenamento das infraestruturas técnicas da rede capilarizada pelo smartphone no território são as estações rádio base (ou antenas), os cabos de fibra ótica nacionais e transnacionais e o espectro eletromagnético. Há uma indissociabilidade entre o fenômeno da urbanização e o meio técnico-científico-informacional num território da dimensão do Brasil, onde a comunicação e a conexão entre os pontos, fundamental e estratégica, sempre foi difícil por ter sido tradicionalmente centralizada. $\bigcirc$ advento do smartphone e a banalização de seu uso transformaram as interações quando um número crescente de pessoas passou a se comunicar.
\end{abstract}

Palavras-chave: Capilarização da informação. Smartphone. Território. Internet. Urbanização.

\section{The dynamics in the current Brazilian urban network and the capillarization of information by smartphone in the territory}

\begin{abstract}
The capillarization of information in Brazilian territory through the smartphone and its spatial implications are the result of the convergence of telephony and internet techniques, whose network expands its reach to meet the increasing demand for connection, under the regulation of public and private agents that determine the implementation and use of these infrastructures. The territorial planning for the technical infrastructures' implementation of the network
\end{abstract}


capillarized by the smartphone in the territory has its main support the base radio stations (or antennas), the national and transnational fiber optic cables and the electromagnetic spectrum. There is an indissociability between the phenomenon of urbanization and the technical-scientific-informational medium in a territory of the dimensions of Brazil, where communication and connection between the points, fundamental and strategic, has always been difficult because it has been traditionally centralized. The advent of the smartphone and the popularization of its use transformed the interactions when an increasing number of people began to communicate.

Keywords: Capillarization of information. Smartphone. Territory. Internet. Urbanization.

\section{La dinámica en la red urbana actual y la capilarización de la información por smartphone en el territorio}

\section{Resumen}

La capilarización de la información en el territorio brasileño a través del smartphone y sus implicaciones espaciales son resultado de la convergencia de las técnicas de telefonía e internet, cuya red expande su alcance para atender a la creciente demanda de conexión, bajo la regulación de agentes públicos y privados que determinan la demanda implementación y uso de estas infraestructuras. El ordenamiento de las infraestructuras técnicas de la red capilarizada por el smartphone en el territorio tiene como soporte principal las estaciones base (o antenas), los cables de fibra óptica nacionales y transnacionales y el espectro electromagnético. Hay una indisociabilidad entre el fenómeno de la urbanización y el medio técnico-científico-informacional en un territorio de las dimensiones de Brasil, donde la comunicación y conexión entre los puntos, fundamental y estratégica, siempre ha sido difícil por haber sido tradicionalmente centralizada. El advenimiento del smartphone y la banalización de su uso transformaron las interacciones cuando un número creciente de personas pasó a comunicarse.

Palabras claves: Capilarización de la información. Smartphone. Territorio. Internet. Urbanización. 


\section{Introdução}

Neste artigo, procurou-se entender como a capilarização das informações pelo smartphone no Brasil se constitui num movimento de grande mudança no uso do território, em razão das novas possibilidades apresentadas à maior parte da população por meio da conexão à internet em pontos contíguos e não contíguos, e pelas formas interescalares de interação que essa mudança propiciou de modo mais frequente e intenso sobretudo nas cidades.

A capacidade de receber e usar as informações em diferentes lugares e o intercâmbio imediato de ideias podem resultar no exercício de relações horizontais, entre indivíduos, ou verticais, quando estes são submetidos ao controle de corporações, Estados e outros agentes políticos e econômicos. Esses agentes expandem sua interferência no campo comunicacional, informacional e cognitivo, influenciando comportamentos e ações no território.

As relações entre o uso do smartphone e o uso do território se baseiam na correspondência entre as redes existentes com mais densidade principalmente nas cidades e na transformação de suas dinâmicas, a partir da inserção e do uso massivo desse objeto técnico que medeia várias formas - complementares, indispensáveis e mesmo antagônicas - entre usuários e corporações que controlam as tecnologias telemáticas e proveem acesso à internet para comunicação, obtenção de dados e produção de informações e vigilância.

Por meio da intensa participação dos indivíduos na rede, as tradicionais relações hierárquicas entre as cidades podem ser relativizadas e às vezes compatíveis com relações heterárquicas, isto é, mais horizontais e com certa equidade entre os centros urbanos. $\bigcirc$ uso do smartphone em todas as faixas de renda e faixas etárias no Brasil, diferenciado por classe social em razão dos valores do serviço e dos dispositivos, permite o encadeamento entre várias escalas - do macro (corporações, instituições, Estados, governos e organizações de solidariedade) ao micro (indivíduos com propósitos de uso pessoal) -, o que dá mais eficiência às ordens e ações hegemônicas capilarizadas no território, produzindo um corte transversal das escalas, sem mediação, entre agentes globais e locais.

As ações possibilitadas pela capilarização pulverizada das informações pelo território estabelecem novas relações espaço-temporais na vida social, como a extração de dados pessoais dos usuários e sua manipulação para várias finalidades, que hoje são decisivas no planejamento e na produção do espaço geográfico, portanto, no devir social de um lugar ou região, estabelecidos por intencionalidades na organização do território.

A atuação dos agentes da rede suporte e da rede serviço, que conectam smartphones à internet, mostra-se fundamental e revela suas implicações na sociedade, cada vez mais condicionada e dependente dos objetos técnicos desenvolvidos com desígnios científicos e informacionais.

\section{A rede urbana brasileira e a distribuição das redes}

A estruturação da rede suporte e da rede serviço da internet que viabilizam a capilarização da informação por meio do smartphone têm uma correlação direta com a caracterização da rede urbana nacional. No processo de urbanização, a rede urbana é o meio pelo qual se realizam efetivamente a produção, a circulação e o consumo. Funcionalmente articulados entre si e constituindo um elemento essencial da rede urbana, os centros urbanos têm os nós que concentram densidade populacional, densidade de objetos técnicos e serviços urbanos que se conectam com os diferentes fluxos entre esses centros (Corrêa, 2001). 
Em determinadas áreas onde se concentram muitas redes, sobretudo de informação e comunicação, é que se produz o meio técnico-científico-informacional, no momento em que os sistemas técnicos são implantados e utilizados, resultando em mudanças no território que, sob novos fundamentos e novos conteúdos de informação, concebem a expansão reticular do sistema, favorecendo o alargamento dos contextos (Santos, 2000), dada a conexão entre lugares próximos e isolados por meio do aperfeiçoamento de técnicas para capilarizar da informação.

A rede urbana é um produto social e histórico em que, pelas relações no espaço, se estruturam as redes da sociedade. As diferenças espaciais decorrentes da constituição dos processos sociais e das diferentes temporalidades condicionam a existência de vários tipos de rede urbana e várias densidades de redes técnicas implementadas desigualmente no território brasileiro.

O sistema de economia de mercado promoveu a atual divisão territorial do trabalho, sob a qual as cidades ficaram muito integradas. $\bigcirc$ Estado foi também teve um papel fundamental na estruturação produtiva do território, em sua integração e no processo de urbanização agindo em conjunto com as empresas, sobretudo as do ramo de telefonia e comunicação. Na rede urbana encontram-se fixos que garantem a realização de transações comerciais e promovem interações diferenciando-as e resultando em especializações produtivas (Corrêa, 1997). A rede urbana é um conjunto de cidades que faz uma intermediação diferenciada de decisões originadas dentro ou fora do território nacional; em geral, essas cidades operam como nós de uma ampla rede com sedes em outros países e, por isso, os sistemas informacionais mediadores são imprescindíveis à divisão internacional do trabalho contemporânea.

Os agentes estruturados em rede e que têm o poder de definir e impor funções são as corporações, frequentemente em parceria com Estados e governos, que possibilitam a integração de pontos selecionados de territórios com papel destacado na economia global. Assim, determinadas cidades se transformam em centros de gestão capazes de comandar as redes urbanas em diferentes países.

A rede urbana brasileira é marcada por uma "complexidade genética, com diversos padrões espaciais, crescente complexidade funcional do seu centros e diversos tipos e intensidade de integração interna e externa" (Corrêa, 2001, p. 95) e, portanto, é composta de diversas acumulações desiguais de tempo (Santos, 2000), em que convivem, no mesmo espaço da cidade, fixos que surgiram no início da colonização e outros construídos no começo do século XXI, sob a ação de diferentes processos que constituem centros urbanos em tempos desiguais.

Logo, a rede urbana nacional não tem um único padrão espacial, pois o território apresenta altas densidades demográficas e de redes técnicas em algumas porções da região Sudeste e nas capitais nordestinas e, ao mesmo tempo, também há baixas densidades nas regiões Norte, Centro-Oeste e Nordeste.

Até meados do século XX, a densidade de funções dos centros urbanos se diferenciava pelos tipos de serviços e bens que distribuía, comercializava ou beneficiava; a divisão territorial do trabalho se configurava pelas funções de cada um, segundo o modelo hierárquico da teoria dos lugares centrais, de Walter Christaller (1966). Essa hierarquia era definida em razão do tamanho, da importância, da dimensão dos fluxos e das funções de cada cidade, relativos à quantidade e à diversidade de bens e serviços que forneciam a sua área de influência, para tornar mais eficiente a economia do Estado. 
A partir das transformações tecnológicas que se refletiram em todas as escalas espaciais pela expansão e capilarização da internet e da banalização do uso dos smartphones no começo do século XXI, a fluidez no território e a segmentação social tornaram-se mais complexas e demandaram, além das inovações no campo, a complexificação funcional dos centros urbanos brasileiros (Corrêa, 2001). Assim, o modelo tradicional de hierarquia urbana já não consegue explicar a rede de cidades brasileiras, pois só a posição de cada centro na atual conjuntura não basta para caracterizar e desvendar sua importância nessa rede.

A divisão territorial do trabalho nos centros urbanos se expande, e a complexidade funcional de cada centro resulta na sua conexão concomitante com várias redes regionais, nacionais e internacionais.

A variedade de agentes, heranças e suas relações são intensificadas por ações que visam tornar mais eficiente e capilarizado o novo paradigma de conexão entre os lugares e regiões não contíguas por meio da implantação de redes pelo Estado e pelas corporações. Nesse momento, essa integração começa a envolver relações interescalares, em que diversos pontos do território se conectam a diversas redes que têm diferentes papéis e obedecem a ordens que emanam de pontos distantes.

A partir da organização em rede, os fluxos, que em outros períodos eram exclusivamente regionais, têm agora um alcance maior, por se conectar com outras metrópoles nacionais e internacionais, capitais regionais ou nacionais e pequenos centros isolados.

A intensidade e velocidade com que se integrou a rede urbana no Brasil se deveram a ações que transformaram a estrutura econômica e as vias de circulação de bens e informações pela implementação de redes de telecomunicação em pontos selecionados do território, principalmente aqueles que tinham já tradicionalmente uma densidade técnica importante. Assim, o processo de capilarização da informação e comunicação por meio dessas redes incorporou novas demandas e um novo fluxo, acompanhando o desenho desigual das densidades técnicas no território. Nesse contexto, a capilarização da informação banal não estratégica se diferencia da informação estratégica. Esta última é extraída e tratada pelas corporações que as monitoram e interpretam por meio de Big Data, ensejando fluxos de informações intraempresas, que podem ser sigilosas e que fluem por redes que não são banais.

Esse processo permite que as interações espaciais se manifestem no espaço envolvendo fixos e fluxos (Santos, 2006). As estruturas fixadas em cada ponto do território possibilitam ações que modificam o próprio lugar segundo os fluxos que elas controlam.

Para Roberto Lobato Corrêa (1997), as interações espaciais são componentes do espaço geográfico resultantes dos deslocamentos multidirecionais de bens, pessoas, capitais e informações com diversas densidades de fluxos e velocidades, de acordo com os objetivos e os meios para estabelecê-los.

Logo, as interações espaciais intensificam e transformam processos de acumulação de capital, pois se sucedem no contexto da divisão social e territorial do trabalho, manifestando as desigualdades de densidades de fluxos, direções e padrões (Corrêa, 1997). As interações espaciais propiciadas pela capilarização da informação por meio do smartphone também repercutem em transformações espaciais, considerando sua distribuição desigual no espaço.

No contexto das metrópoles brasileiras, marcadas pela concentração demográfica e pelo setor de serviços, a população usa muito o smartphone, intensificando a integração a movimentos e redes de trocas e distribuindo serviços estratégicos para outros pontos do território. 
$\bigcirc$ movimento de metropolização se apoia numa rede de transportes e telecomunicações por meio das quais se desenvolve um processo simultâneo de descentralização e centralização. Esse movimento determina as condições de crescimento que acompanha a expansão das redes, sobretudo as de comunicação do período atual.

A rede de infraestruturas que fornece sinal de internet exige a instalação de objetos na cidade a partir de princípios técnicos específicos, com torres de transmissão, como as ERB, fios de cobre e de fibra ótica, tanto em postes como em dutos subterrâneos, estabelecendo conexão com vários níveis de rede.

A oferta e a qualidade dos serviços e da instalação dessas infraestruturas são espacialmente desiguais, pois as empresas buscam o retorno dos investimentos onde há demanda. Há uma relação direta com a implementação das infraestruturas técnicas e o desenho da cidade: muitas delas servem como dinamizadores para a ocupação de determinadas áreas, por sua instalação planejada e pela relação entre especulação imobiliária e poderes públicos, pois permitem a conexão entre vários agentes, e sua expansão generalizada leva à banalização do uso e acesso aos meios da cidade.

A integração entre os pontos numa rede urbana é tão mais relevante quanto mais dispersas estão as condições de produção e o consumo de mercadorias no espaço, e, portanto, as redes expressam a escala das ações sociais (Dias, 2005).

Segundo Corrêa (2001), as redes são um conjunto de localizações geográficas interconectadas por certo número de ligações e, no arranjo e na ampliação das trocas sob o sistema capitalista, são imprescindíveis para que a divisão territorial do trabalho tenha a atual escala global e funcione segundo as variadas redes técnicas imbricadas que se manifestam de forma complexa nas redes urbanas, com seus centros especializados e hierarquizados por onde fluem diversos elementos, materiais e não materiais. Assim, as cidades que abrigam sedes ou filiais de corporações transnacionais "multifuncionais" e "multilocalizadas" concretizam os numerosos e complexos nós das redes que reforçam uma organização desigual do espaço, ao mesmo tempo fragmentada e globalizada.

$\bigcirc$ arranjo espacial das interações se realiza por pontos e linhas e, no contexto das redes que constituem e viabilizam o uso dos smartphones, dão-se as interações espaciais não contíguas. Consideramos que as interações espaciais são os meios nos quais "as formas espaciais articulam-se entre si, realizando as funções que os processos espaciais thes atribuíram e [...] constituem uma unidade, fundamentais para compreender a espacialidade humana" (Corrêa, 2016, p. 122). Portanto, as interações espaciais são também reflexo e condição dos processos sociais.

As formas dessa rede que enseja as interações espaciais realizam os processos e cumprem ordens que são determinadas tecnicamente, para cada uma de suas funções, através da cadeia complexa que as compõe, formada por elementos humanos e não humanos (Latour, 2001). A história da reprodução das sociedades é constituída de interações espaciais, e a cada período corresponde um tipo de interação; a partir da primeira revolução industrial e da consolidação do capitalismo, elas se tornaram mais complexas, intensas, superpostas e interligadas.

Entendido como acumulação desigual de tempos (Santos, 1996), o espaço acumula também interações espaciais que variam segundo o período e o lugar onde ocorrem. Logo, o período atual "é um capítulo em uma longa história das interações espaciais, da espacialidade humana, envolvendo o permanente esforço de superação do espaço pelo tempo" (Corrêa, 2016, p. 125). 
As categorias distância, intensidade e direção são imprescindíveis para caracterizar as interações espaciais e interpretar a espacialidade humana. Ademais, a duração, a velocidade, a frequência, o ritmo e o período em que acontecem os eventos são importantes para observar os fenômenos sob a ótica do tempo.

A capilarização da informação por meio do smartphone proporciona um tipo de interação espacial caracterizada por sua inserção numa rede de múltiplos circuitos, com uma distribuição de pontos ligados a atividades econômicas, políticas e sociais que se dão por meio de vias e numerosos pontos e nós.

Os pontos que conformam essa rede são os agentes e suas relações: os agentes que têm mais de uma são chamadas de nós e conformam uma rede quando possibilitam e são demandados por outro ponto ou outro nó. Os pressupostos dessas redes são sua velocidade e sua flexibilidade ao conectar e desconectar pontos e ações remotas, o que provoca uma instabilidade potencial de cada ponto ou nó, e parte de sua força está na habilidade de fazer e desfazer rapidamente as conexões (Duarte; Frey, 2008).

Essa rede funcional tem estruturas que desenham o território e perfazem conexões manipuladas por agentes que podem produzir relações e fazer circularem informações. Essa é uma rede de ideias ou de modos de pensar e agir conectando pontos remotos. As redes sociais utilizadas por meio dos smartphones se dão como um sistema interescalar que emite ordens para todos os pontos conectados. Presentes em muitos âmbitos da vida de cada indivíduo, esses fluxos informacionais constituem redes de ações que não só disseminam informação, mas formam redes que desencadeiam ações muitas vezes momentâneas e nem sempre mapeáveis.

\section{Distribuição dos smartphones e usos no território}

No período atual, os sistemas técnicos e suas sucessivas inovações se difundem rapidamente por causa da aceleração entre sua concepção e seu desenvolvimento, concomitante com uma racionalidade imposta por meio da implementação de vários objetos técnicos em rede, imprescindíveis à acumulação capitalista atual, levada a um grande número de lugares (Santos, 1996). Esses sistemas são irreversíveis na medida em que se convertem em necessidades, pois podem ser usados ordinariamente por todos os estratos da população.

Tais redes têm suas malhas e nós multiplicados e possibilitam a articulação e o domínio de territórios não contíguos (Raffestin, 1985). Assim, o caráter político das redes técnicas pressupõe controle, "facilitam a obtenção de legitimidade, a mobilização das forças extra-locais, as alianças necessárias para influir em decisões de foros maiores, e é possível adquirir uma fluidez escalar que pode servir inclusive para reforçar o poder local" (Dorfman, 1995, p. 106).

Esses sistemas encadeados medeiam muitas interações espaciais sob as particularidades da formação socioespacial brasileira, cujo território tem dimensão continental e profundas desigualdades regionais como as de infraestrutura. Ao mesmo tempo, a crescente internacionalização do capital e a ascensão das corporações resulta na procura por lugares mais rentáveis e, assim, os projetos locais são condicionados por estratégias globais (Santos, 1994). 
A integração em rede não é só um fator de competitividade, mas também de acesso a um direito fundamental: a comunicação. Segundo o Instituto Brasileiro de Geografia e Estatística, com base na Pesquisa Nacional por Amostra de Domicilios (IBGE, 2016), a quantidade e qualidade da conexão da internet por meio do uso do smartphone, em comparação com outros aparatos de conexão, por renda, por unidade da federação e por região, tem um uso crescente e distribuído territorialmente (Mapa 1).

\section{Mapa 1 - Número de usuários de smartphone no Brasil, por unidade da federação e por região metropolitana, 2016}

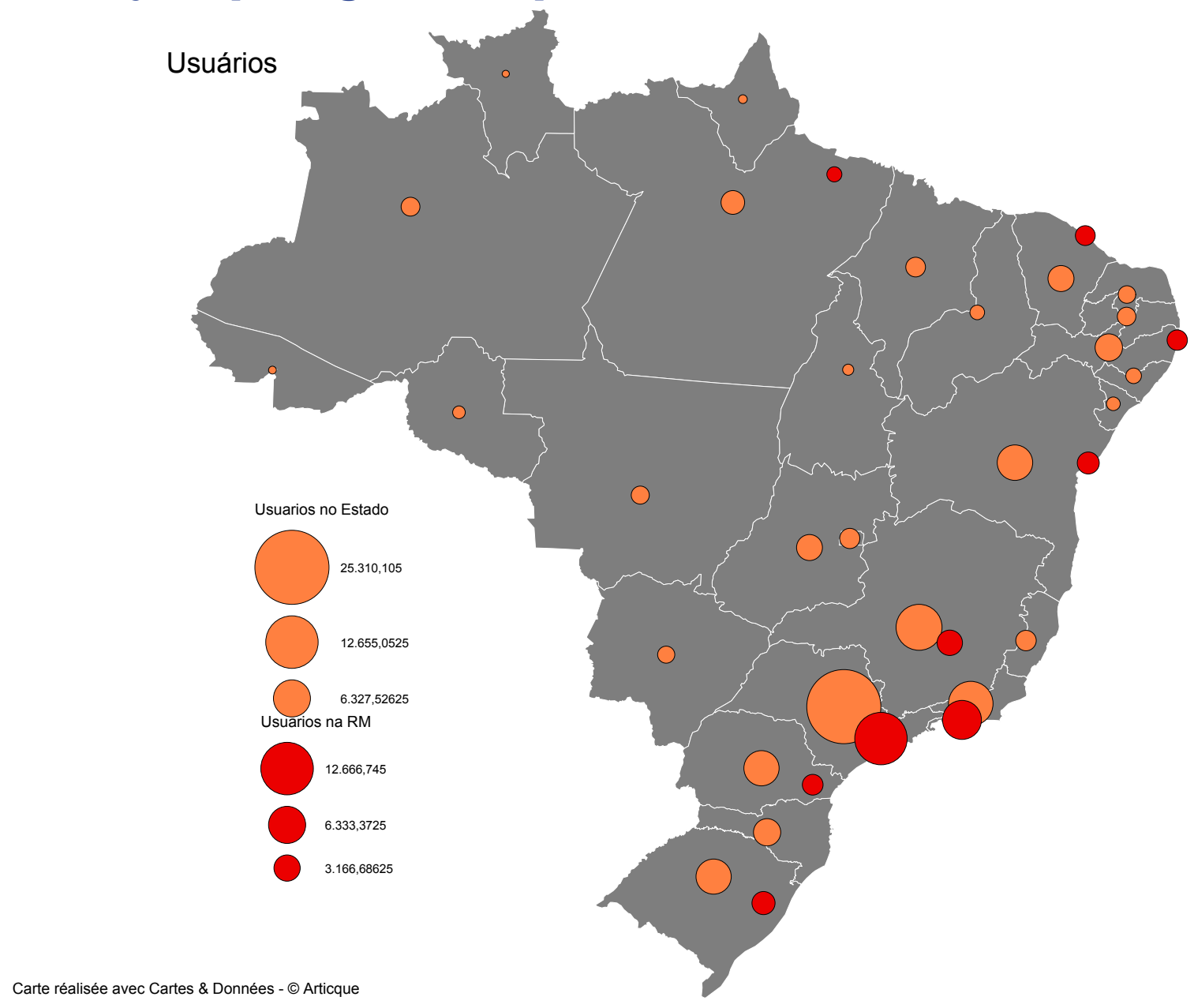

fonte: IBGE (2016). organização: Mait Bertollo. elaboração: Hervé E. R. Thery.

No Mapa 1, vemos o número de usuários de smartphone por unidade da federação e por região metropolitana. A concentração é maior na região Sudeste, principalmente no estado de São Paulo e na região metropolitana da capital. Na região Norte e em alguns estados do Nordeste, observamos uma menor densidade de infraestrutura de conexão e menos acesso à rede. Considera-se o movimento de informacionalização do espaço (Santos, 1994) condição indispensável ao exercício do poder econômico e político, entretanto, a distribuição dos usuários de smartphone revela que as novas variáveis não se distribuem uniformemente na escala nacional. 
ponto central é o acesso que se provê a indivíduos, empresas e instituições aos vetores informacionais: acessam-se notícias, dados etc., e também se trocam informações em tempo imediato, simultâneo. $\bigcirc$ número de usuários em determinada parte do território e sua distribuição pelas cidades revela as dinâmicas espaciais, uma vez que também indica a densidade da interação entre indivíduos.

Isso mostra que algumas ações hegemônicas, sejam das corporações ou do Estado, se estabelecem e realizam por intermédio de objetos técnicos em determinadas porções do espaço que têm capacidade de retornar o valor investido.

A maior densidade do uso de smartphones se verifica na população com maior renda, espacialmente aglomerada no Sudeste e no estado de São Paulo (IBGE, 2016). Nas regiões Norte e Nordeste, onde o número de usuários é menor, o uso é mais concentrado em usuários com renda a partir de dois salários-mínimos.

Os dados expõem o uso do smartphone no território e as possibilidades de interação espacial e participação dos indivíduos nessas redes técnicas, onde eles se relacionam, influenciam e são influenciados pelas articulações proporcionadas pelo vetor informacional.

Por meio do smartphone, os indivíduos produzem a contiguidade e a convergência dos momentos nessa rede, pois a capilarização da informação banal altera o tipo de interação espacial e pode produzir uma nova forma de realizar e/ou influenciar comportamentos em vários pontos e em centros urbanos, que são a principal base territorial desse sistema técnico que promove a instantaneidade e simultaneidade na rede urbana e na vida de relações entre as cidades.

\section{Interações espaciais condicionadas pelo uso do smartphone: difusor de in- formação e motivador da comunicação}

As interações espaciais são componentes do espaço geográfico que têm a propriedade de atenuar, intensificar e transformar processos preestabelecidos e se refletem nas transformações espaciais, com desenvolvimentos desiguais do espaço, constituindo um amplo e complexo conjunto de deslocamento de pessoas, mercadorias, capital e informação sobre o espaço geográfico e podem manifestar maior ou menor intensidade, com maior ou menor frequência, distância e diversas direções e velocidades. Logo, as interações espaciais são parte da reprodução e processo de transformação social (Corrêa, 1997).

É através das redes que as interações espaciais efetivamente se realizam, a partir dos atributos dos lugares e das possibilidades, como no caso da capilarização da internet e das informações pelo uso do smartphone, que são uma forma de compreender a espacialidade humana em sua manifestação comunicacional.

Consideramos aqui que a comunicação é a troca e difusão de informações (estímulos, imagens, símbolos, mensagens) possibilitada por um conjunto de regras explícitas ou implícitas, que são os códigos, e que toda cultura é uma estrutura de comunicação que só pode ser compreendida pela decifração de seu código (Sodré, 1976). Assim, o fenômeno da cultura de massa só se viabilizou com o desenvolvimento do sistema de comunicação por mídia, com o progresso e a multiplicação de veículos de massa como jornais, televisão, rádio, filmes, discos, revistas e, no começo do século XXI, sites e aplicativos conectados à internet, aliados aos fenômenos de urbanização, formação de públicos de massa e aumento da necessidade de lazer. 
A informação é interpretada como um instrumento para ordenar (ou reordenar) a experiência social do indivíduo "promovendo o seu convívio, já que a informação tem uma função política, no sentido de constituição ou formação da polis" (Sodré, 1976, p. 19). O produto da cultura de massa é resultado das intencionalidades do sistema comunicador, definidas pela publicidade, pelas ideologias predominantes, pelos interesses das empresas de comunicação etc., que condicionam as relações entre o produtor da obra e o consumidor, gerando uma mensagem específica (Sodré, 1976, p. 19).

O uso banalizado do smartphone, objeto de comunicação e informação de uso individual, privado e subjetivo, pode ser fixo e ao mesmo tempo fluxo - é um veículo contemporâneo da cultura de massa. Ele é a ponta da capilarização da rede de internet e favorece interações escalares do global ao local que se difundem, de certa maneira, por todos os estratos sociais da população brasileira.

A distribuição desse uso por compartimentos do espaço estruturados a partir da divisão social e territorial do trabalho e das divisões políticas é um dos elementos funcionais da expansão do capital, tanto as divisões internas dos territórios nacionais quanto as divisões em formações socioespaciais do planeta, que são interescalares.

\section{Incidência das normas nas cidades: empresas de telecomunicação, Estado e o condicionamento do uso das redes}

As normas desse conjunto complexo de redes e os agentes que as comandam determinam os papéis do Estado, das empresas, das organizações não governamentais e da sociedade civil organizada no uso do território para diversos interesses em várias escalas. Assim, a "regulação do território é hibrida porque há vários agentes em seu exercício. Eles produzem normas jurídicas, leis; e não somente condicionamentos conjunturais por mecanismos de pressão isolados" (Antas Jr., 2005, p. 208).

Esses processos incidem diretamente nas cidades, que se transformam por meio de sucessivas combinações de objetos técnicos, fixos e fluxos que conectam sistemas urbanos e assim fomentam e mantêm a aceleração contemporânea, que é "resultado também da banalização da invenção, do perecimento prematuro dos engenhos e de sua sucessão alucinante. São, na verdade, acelerações superpostas, concomitantes" (Santos, 1994, p. 12). A cidade é um grande aglutinador de conjuntos de sistemas tecnológicos conectados à rede global de telecomunicações, base da produção e das trocas globais, e ao mesmo tempo articula e oferece meios para que se generalize o uso do smartphone, que responde ao meio técnico-científico-informacional nas escalas global, nacional, regional e local, mas não está presente na extensão territorial que essas escalas frequentemente sugerem, e sim em manchas desse meio cuja ação se dá nessas escalas.

As cidades ampliam seu poder e passam de lugar do consumo e produção de bens materiais a ser também o lugar da circulação de todos os tipos de bens e informações, fundamentais nas estratégias de expansão dos negócios das corporações de telecomunicação.

O smartphone efetiva na cidade muitos e vários aplicativos que imergem os indivíduos nessa rede, capazes de promover uma multiplicidade de encontros e conexões que podem ser temporárias e reativáveis, em grupos diversos, realizados entre distâncias sociais, profissionais, geográficas e culturais. 
Para Murray (2003) e Jenkins (2006), a participação nas redes sociais transforma a cultura contemporânea por meio da atuação coletiva dos indivíduos, principalmente nas cidades, o que transforma as práticas comunicativas tornando complexas as relações entre indivíduos e conteúdos digitais, sobretudo a partir das mudanças socioeconômicas expressas na disseminação das redes de internet no Brasil e no planeta.

Os indivíduos são expostos a várias experiências em seu cotidiano, relativas a novos dispositivos, novas plataformas ou novas aplicações que permitem interatividade e compartilhamento, em diversos níveis, entre pessoas e máquinas, gerando diferentes usos, apropriações e comportamentos individuais e coletivos.

$\bigcirc$ aumento dos acessos móveis no Brasil desde a última década mostra a densidade de uso e de transformações nas práticas comunicativas (Gráfico 1).

\section{Gráfico 1 - Acessos móveis no Brasil, em milhões, 2016}

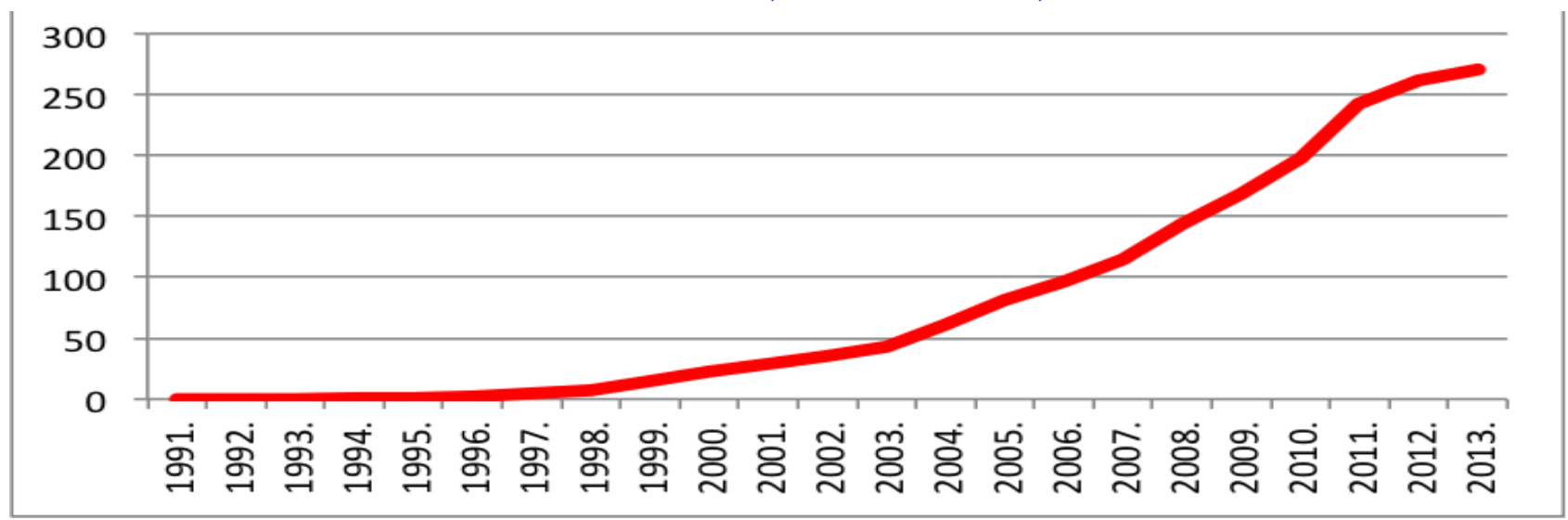

fonte: Atlas Brasileiro de Telecomunicações (2016). elaboração: Mait Bertollo.

No Gráfico 1, verifica-se o importante aumento dos acessos móveis no Brasil no início do século XXI, conferindo às cidades, sobretudo às metrópoles, a base para consolidar e adensar as redes. A pressão por mais conectividade nas porções com mais habitantes e empresas induziu a implementação de aparatos técnicos como ERB, cabeamentos etc. para o acesso à rede serviço.

A popularização do uso do smartphone e suas múltiplas funções subordinadas ao funcionamento da internet e à capacidade de tráfego das informações, têm no atual período cifras que, relacionadas aos fluxos, crescem exponencialmente: entre 2014 e 2015, o tráfego global de informações foi equivalente a 127 bilhões de DVD. 11 bilhões por mês e 15 milhões por hora. A cada oito minutos, troca-se o mesmo volume de informação de todos os filmes já feitos no planeta, e o tráfego global em 2015 foi 21 vezes o de toda a internet em 2005. Numa escala global, esse montante informacional pode ser dividido por 5,9 gigabytes per capita. Em 2016, o total do tráfego ultrapassou a unidade zetabytes (1021 bytes) (Comitê Gestor da Internet, 2016, p. 13).

Em escala nacional, o tráfego médio de internet cresceu 13\% por mês em 2015 e atingiu 1,7 exabytes por mês, o equivalente a 5 bilhões de DVD por ano. Em 2015, o volume de tráfego foi 150 vezes maior que em 2005 (Comitê Gestor da Internet, 2016). A magnitude desse 
volume de dados caracteriza um "dilúvio informacional" (Lévy, 2000), em que a significância da informação no cotidiano altera as práticas da sociedade num contexto em que também aumentam sua criação e difusão.

No Brasil, em 2014, os smartphones se tornaram os aparelhos preferenciais para se conectar à internet, ultrapassando os computadores. A conexão chegou a 80,43\% dos domicílios: 29,6 milhões dos 36,8 milhões de domicílios acessavam a rede por smartphone, e a porcentagem de computadores era de 63,3\% (IBGE, 2016).

\section{Uso do smartphone no território brasileiro: redes de conexão e acesso}

Definidoras da vida cotidiana e com crescente importância na circulação e comunicação de informações, as redes são produto e condição social, historicamente construídas e dotadas de intencionalidades. No caso da conexão do smartphone à internet, seu uso só se concretiza se existe uma conexão satisfatória.

Os usos do smartphone e a qualidade da conexão são diferenciados segundo a classe social, em que há marcas claramente definidas sobre quem tem acesso livre a variados tipos de serviços e quem não tem, impactando vários âmbitos, inclusive o direito essencial ao acesso à internet, previsto no Marco Civil da internet, à formação de opinião, por exemplo.

A rede serviço é acessada por meio do smartphone principalmente por aplicativos; no Brasil, 83\% dos acessos são para mensagens instantâneas (Comitê Gestor da Internet, 2016). Há uma importante mudança nas práticas culturais e na comunicação entre as pessoas conectadas (Gráficos 2-4).

\section{Gráfico 2 - Dispositivos de acesso no Brasil, em milhões de pessoas, por região, 2016}

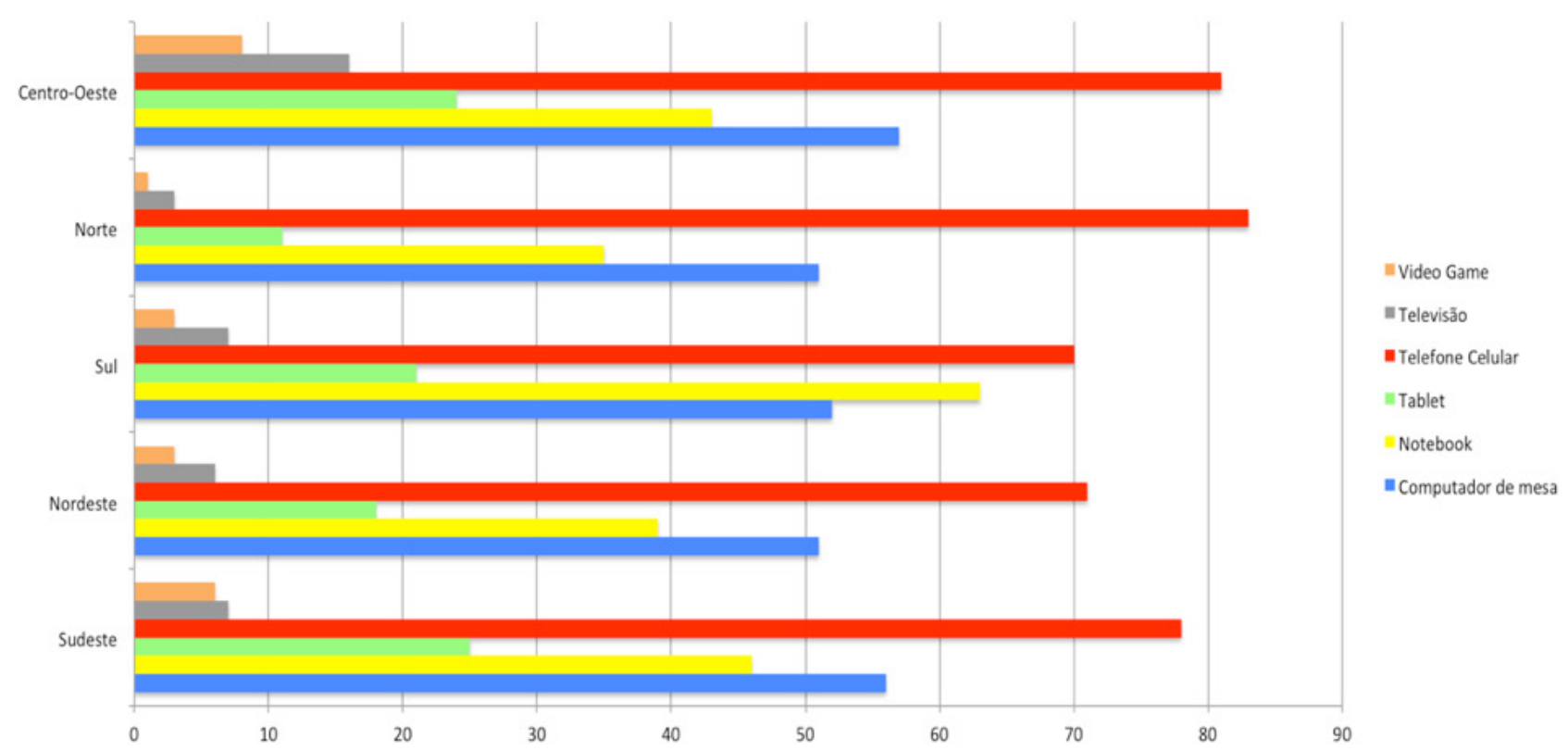

fonte: Comitê Gestor da Internet (2016). elaboração: Mait Bertollo.

Quanto ao uso de dispositivos, o Gráfico 3 mostra a primazia do smartphone e seu peso no acesso à informação e à comunicação em todas as regiões brasileiras. 
Gráfico 3 - Dispositivos de acesso no Brasil, em milhões de pessoas, por renda, 2016

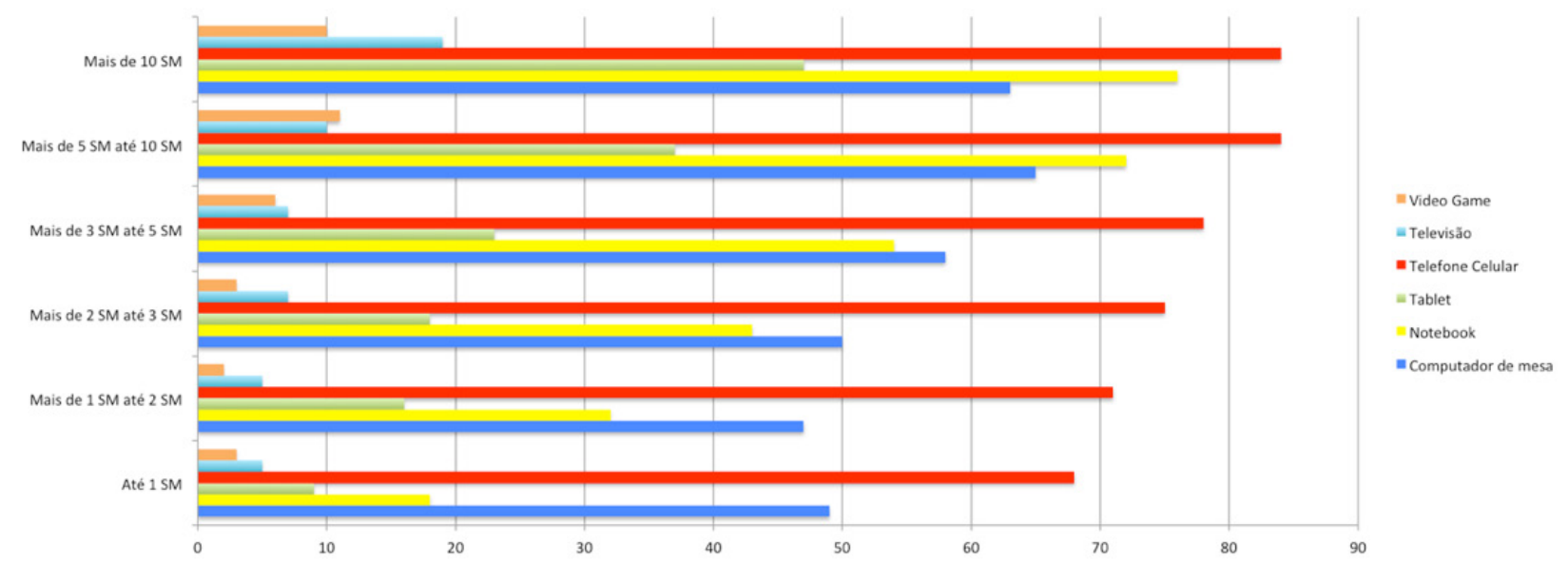

fonte: Comitê Gestor da Internet (2016). elaboração: Mait Bertollo.

Em todas as faixas de renda se usa smartphone, esse objeto que reúne as funções do telefone e de computador, e é esse e uso massivo que estabelece novas práticas de comunicação e da capilarização da informação no Brasil.

\section{Gráfico 4 - Acessos à internet no Brasil, em porcentagem de pessoas, por renda, 2016}

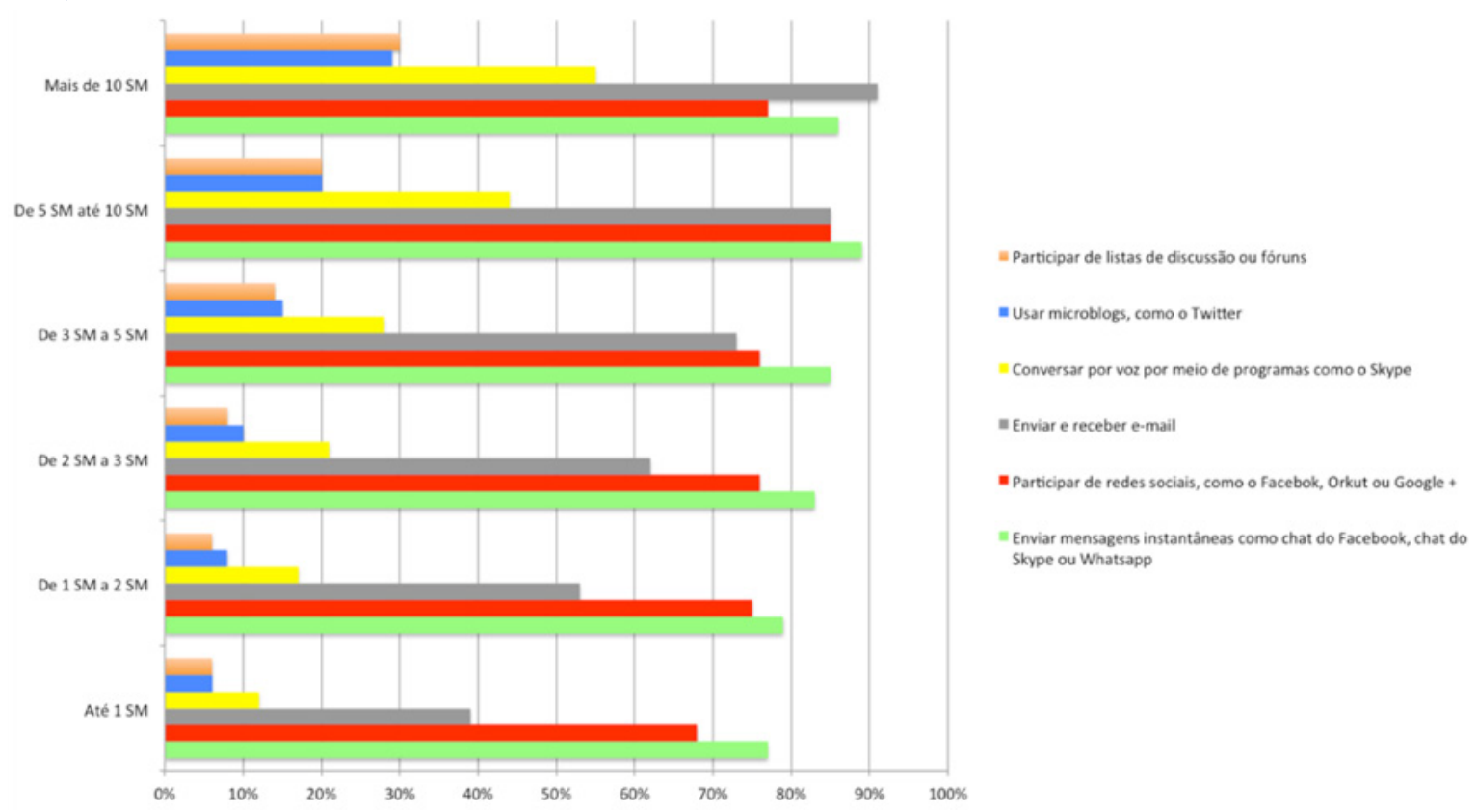

fonte: Comitê Gestor da Internet (2016). elaboração: Mait Bertollo.

Em todas as faixas de renda, prevalece o envio/recebimento de mensagens instantâneas por WhatsApp, Skype ou Facebook, mostrando a força desses aplicativos nas relações comunicacionais, substituindo cada vez mais os dados de voz. Em segundo lugar, está clara a força das redes sociais, sobretudo do Facebook, no cotidiano dos indivíduos e do coletivo. 
Com uso crescente, as redes sociais são ferramentas de propagação de informações que condicionam vários tipos de engajamento, potencializam debates e induzem o crescimento também do volume e da velocidade das informações produzidas em rede, conformando uma lógica da ação comunicacional e informacional no território. Para que essas redes sejam acessadas e também criadas, há um importante impacto dos componentes técnicos e políticos dessa infraestrutura imbricada que resulta em impactos territoriais.

Segundo a Pesquisa Nacional por Amostra de Domicílios Contínua (PNAD) de 2016 (IBGE, 2016), em 5,4\% dos domicílios não havia nenhum tipo de telefone, notadamente nas regiões Nordeste (10 \%) e Norte (11\%). No Centro-Oeste, são 2,4\% dos domicílios, no Sul 3\% e no Sudeste 3,2\%.

Os smartphones estão presentes em $92,6 \%$ dos domicílios do país, contra um pequeno número de telefones fixos em todas as regiões (Gráfico 5).

\section{Gráfico 5 - Percentual de telefones fixos e smartphones nos domicílios, por região, Brasil, 2016}

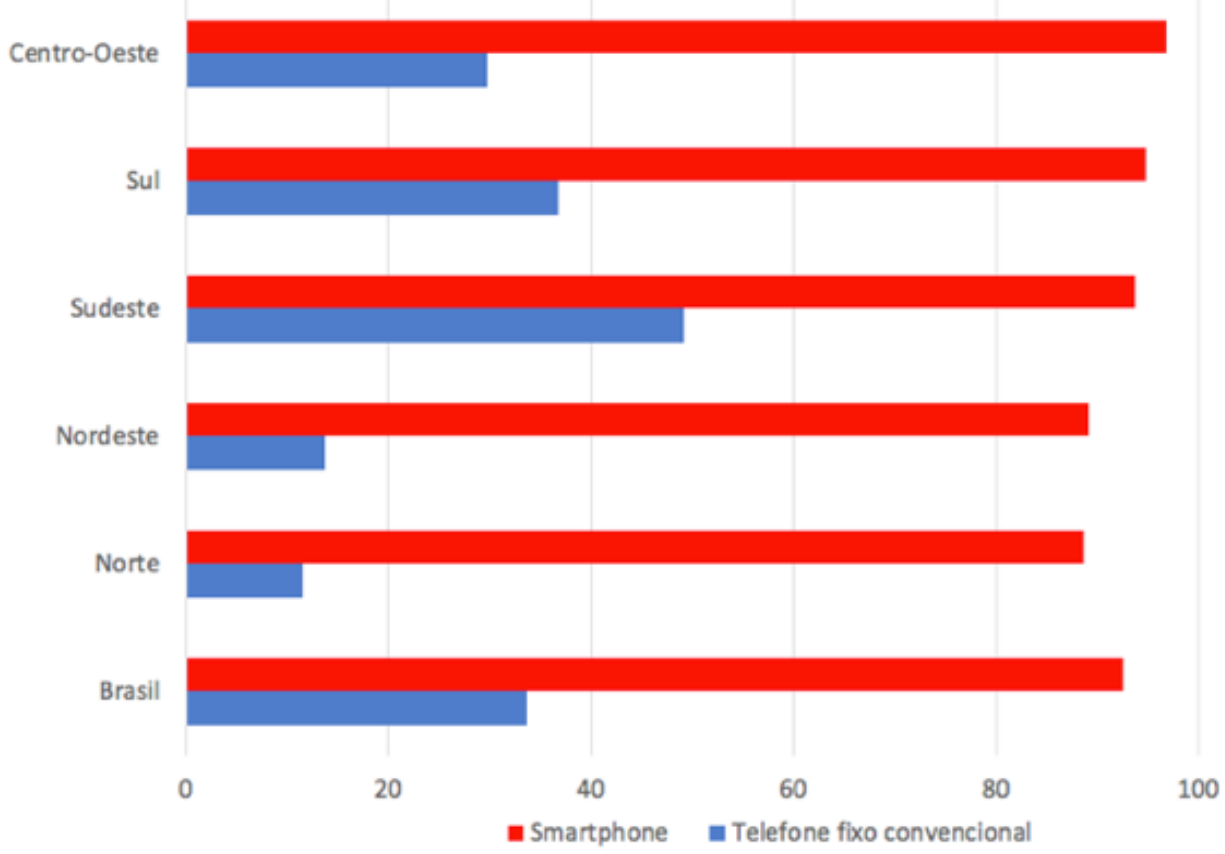

fonte: IBGE (2016). elaboração: Mait Bertollo.

A rede é, por excelência, um instrumento de poder (Raffestin, 1985) e ainda tem o potencial de operar e viabilizar mudanças ou fortalecer permanências (Dias, 1995). A rede de comunicação implementada favorece determinados arranjos espaciais em detrimento de outros, tornando densos certos fluxos e criando e aumentando a intensidade dos campos de força, integrando desigualmente os territórios, agravando assimetrias e seguindo o peso de atividades econômicas preexistentes (Dias, 1995).

Para permitir a conexão do smartphone, o território brasileiro está dotado de 92.116 ERB distribuídas desigualmente (Telebrasil, 2018) e utilizadas principalmente pelas grandes empresas de telecomunicação. As ERB foram mapeadas para verificar seu arranjo espacial a 
partir do banco de dados da Anatel. Aplicaram-se informações como o nome da operadora, seu CNPJ, o código e a localização de cada ERB (latitude e longitude em graus), o que permitiu mapear cada ponto e mostrar sua concentração nas áreas urbanas e em determinadas regiões e unidades federativas, seguindo o padrão de concentração da densidade técnica no Sul e no Sudeste e nas capitais das regiões Centro-Oeste, Nordeste e Norte.

\section{Mapa 2 - Distribuição de ERB no território brasileiro, 2018}

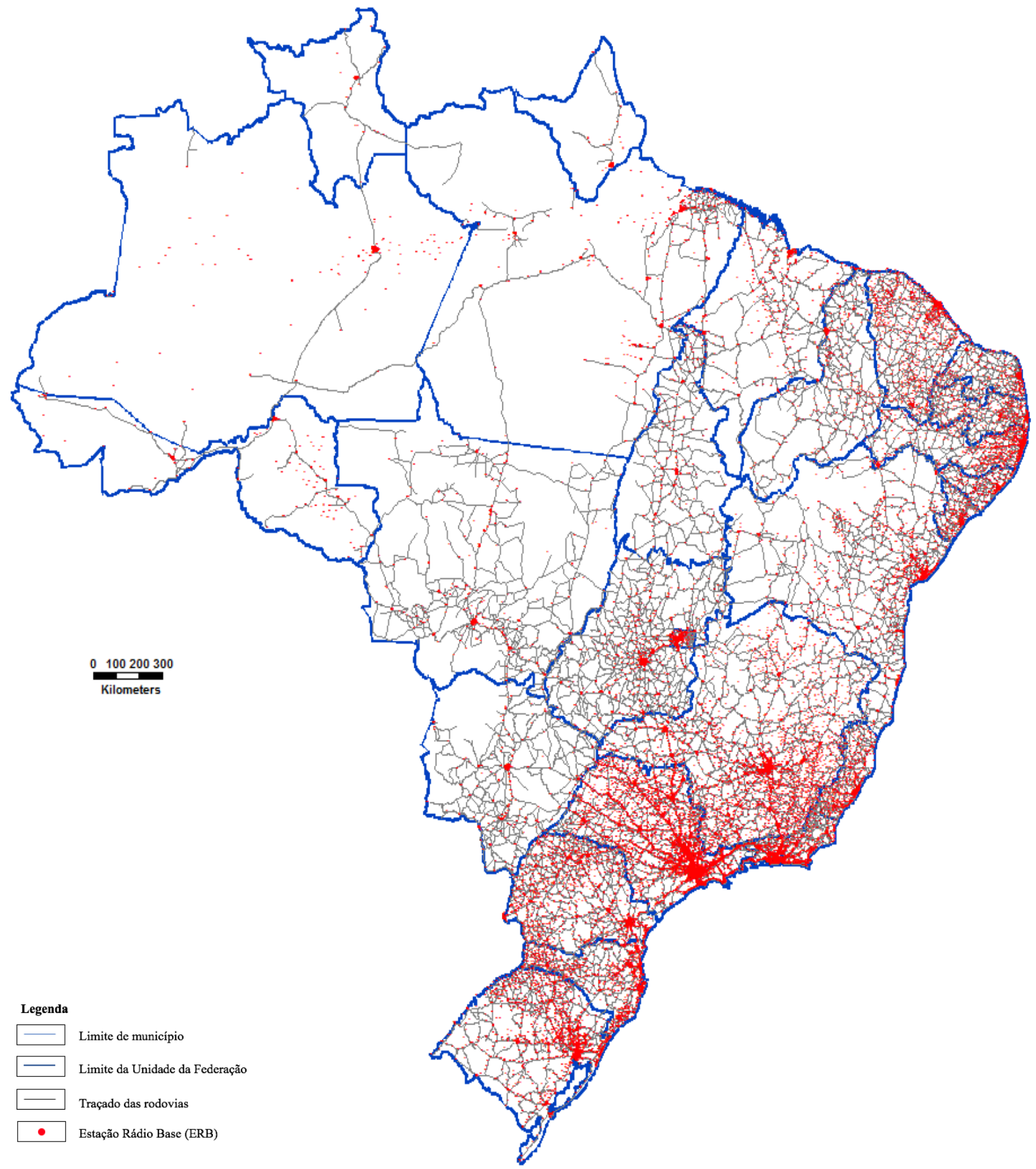

fonte: Anatel (2018). organização: Mait Bertollo. elaboração: André Rodrigues Nagy. 
A distribuição das ERB pelo território brasileiro é essencial ao funcionamento das redes 2G, 3G e 4G, e elas operam numa vasta área, permitindo a partilha ininterrupta da transmissão sem interferências quando os usuários se movem, mesmo em veículos motorizados. Essas redes usam o espectro licenciado e foram projetadas com tecnologia atualizada para redes sem fio, incluindo o serviço de voz. A principal característica dessa estrutura é oferecer cobertura onipresente e contínua, suportada por uma ERB que estende a conexão a vários quilômetros de distância. As estações estão interligadas por uma rede de backhaul, que também fornece interligação com a rede fixa. Os Mapas 3-7 derivam do Mapa 2, ressaltando a distribuição de ERB em cada região brasileira.

\section{Mapa 3 - Distribuição de ERB na região Centro-Oeste, 2018}

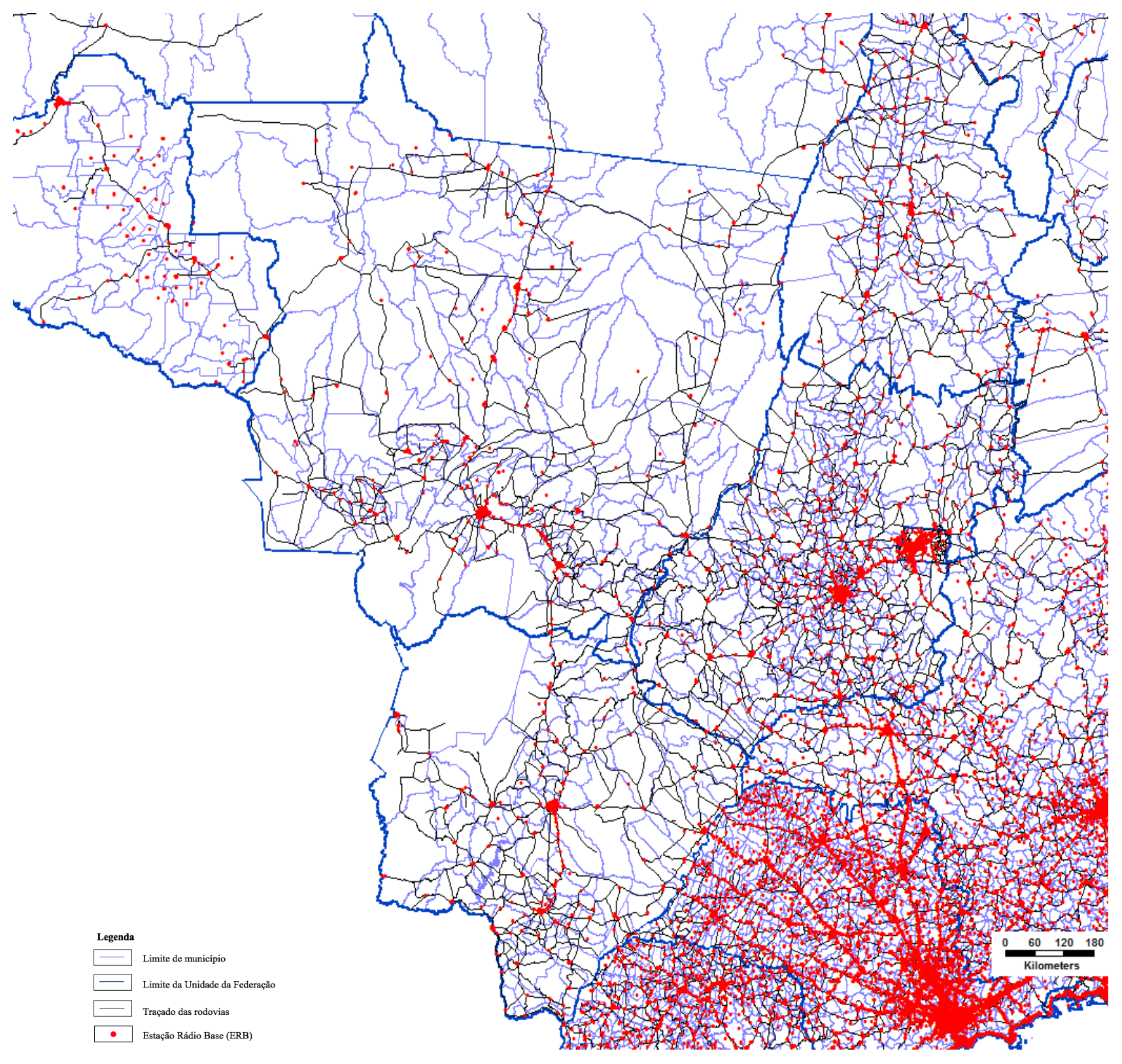

fonte: Anatel (2018). organização: Mait Bertollo. elaboração: André Rodrigues Nagy. 
Mapa 4 - Distribuição de ERB na região Norte, 2018

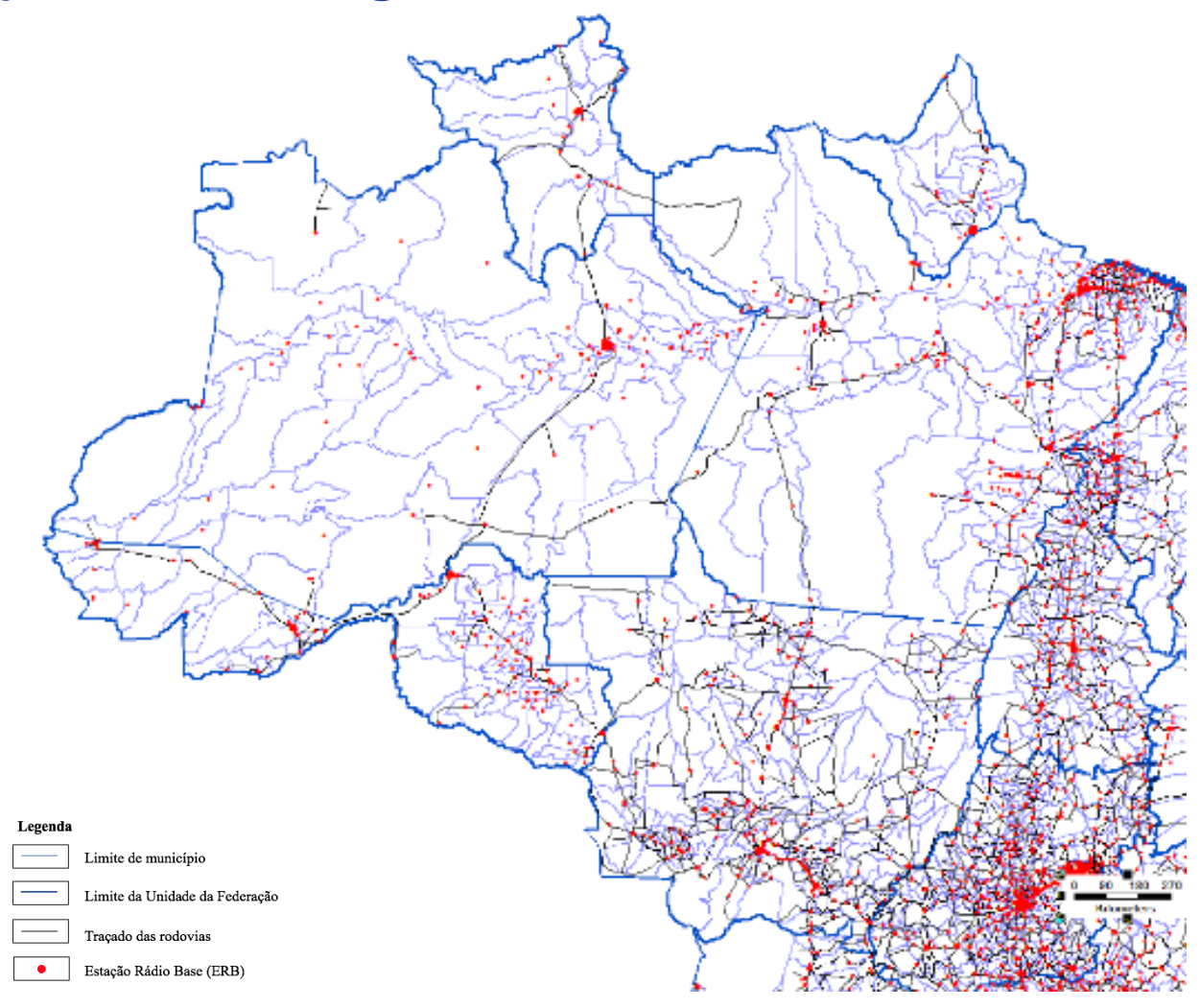

organização: Mait Bertollo.

fonte: Anatel (2018). elaboração: André Rodrigues Nagy.

Mapa 5 - Distribuição de ERB na região Nordeste, 2018
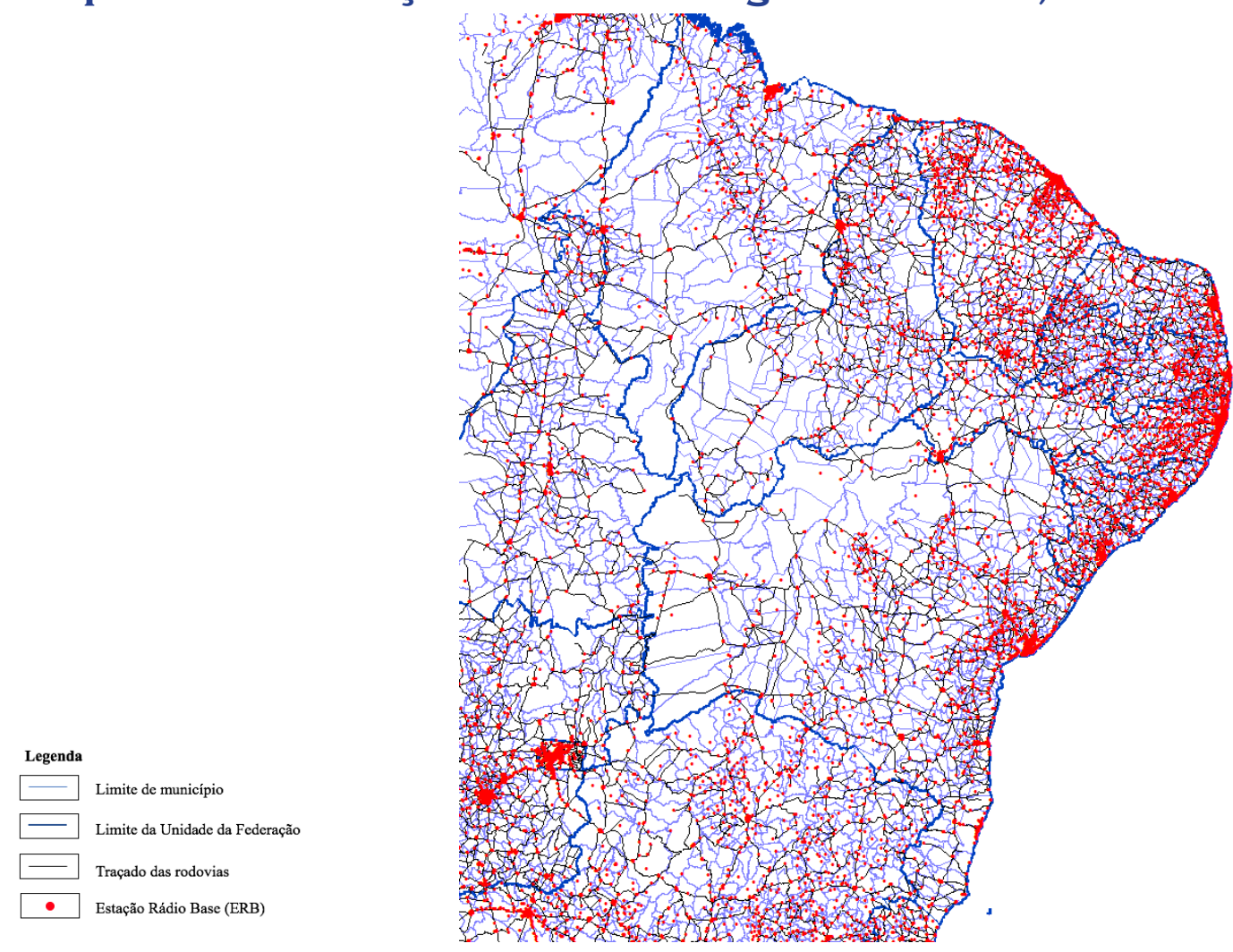
Mapa 6 - Distribuição de ERB na região Sul, 2018
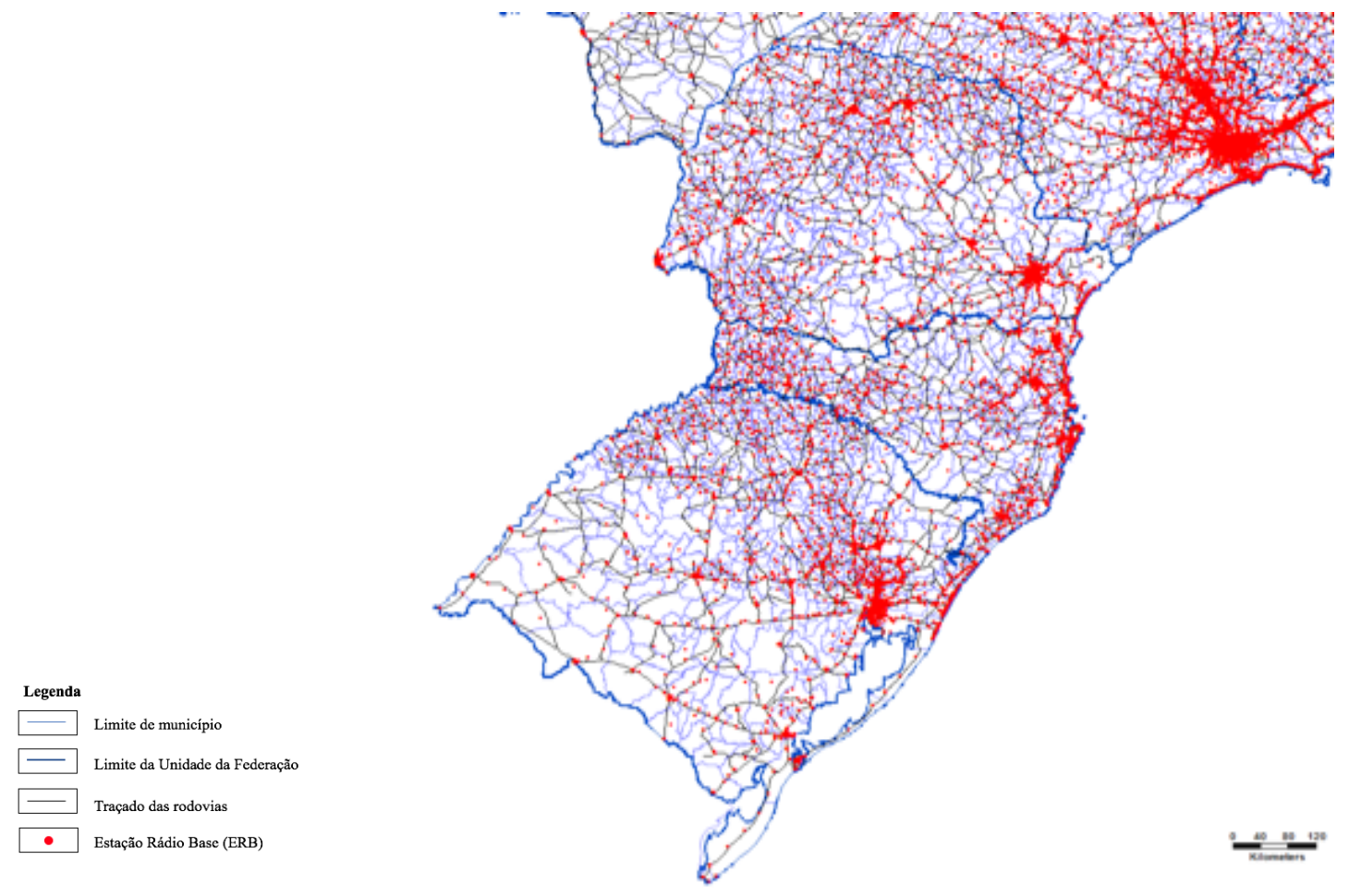

fonte: Anatel (2018). organização: Mait Bertollo. elaboração: André Rodrigues Nagy.

\section{Mapa 7 - Distribuição de ERB na região Sudeste, 2018}
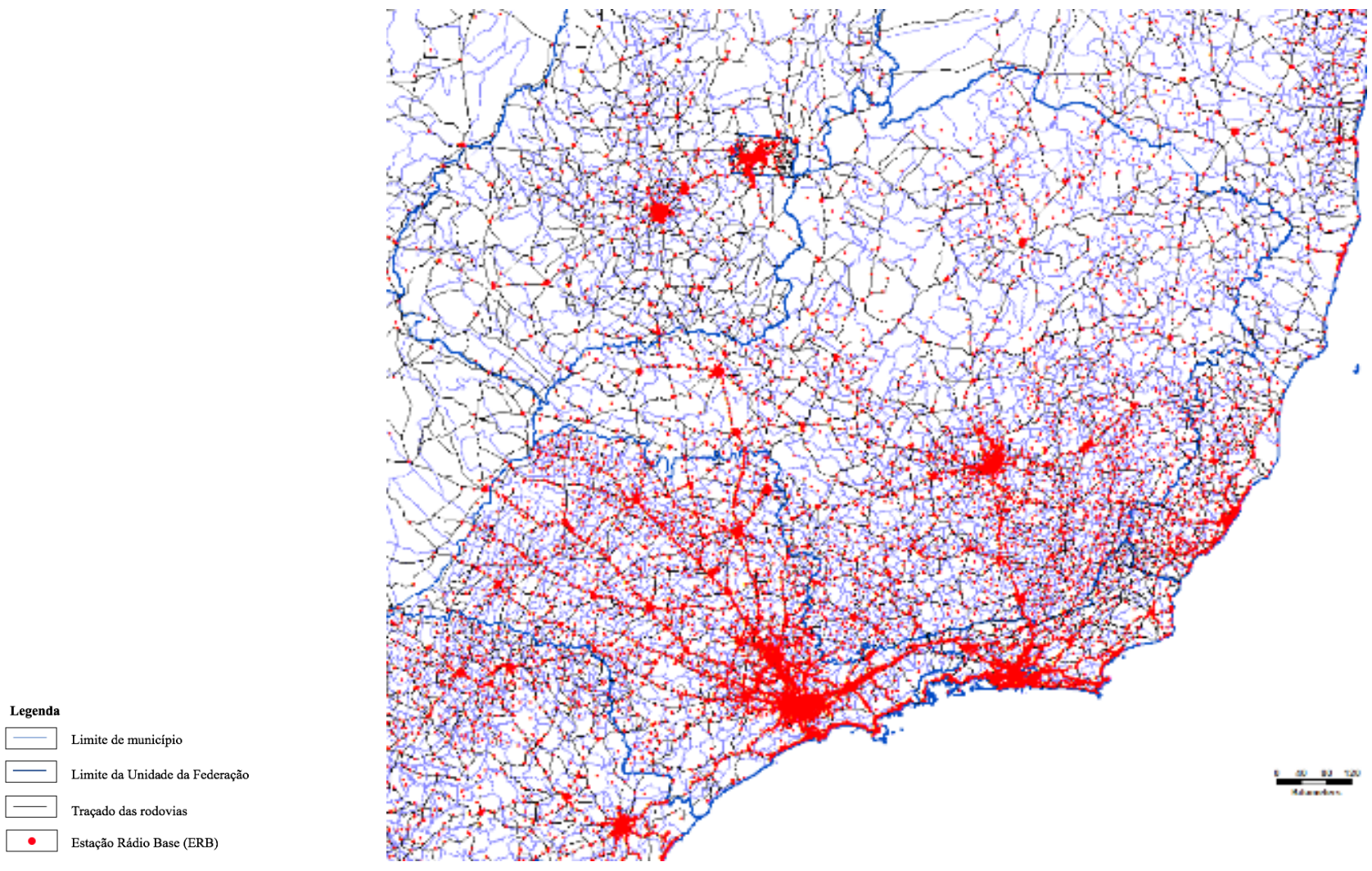

fonte: Anatel (2018). organização: Mait Bertollo. elaboração: André Rodrigues Nagy. 
Verifica-se no Mapa 2 a disparidade da implementação dessa rede no território nacional, com a tradicional concentração no Sul e no Sudeste, ao longo do litoral nordestino e nas capitais, evidenciando a menor densidade de infraestruturas de comunicação na região Norte, ainda que haja pontos pulverizados pelo território. Assim, compreende-se a possibilidade de um novo funcionamento, uma nova organização e um novo uso do território a partir da emergência de novas tecnologias pela capilarização da informação por essa rede, baseada numa integração eletrônica corporativa de pontos selecionados (Castillo, 1999).

Nos Mapas 3-7, que focam as regiões brasileiras, é possível observar que a distribuição de ERB é mais comum ao longo de rodovias, reflexo de especializações funcionais que definem os centros urbanos ligadas à capilarização da informação pelo território.

As manchas, linhas e pontos vermelhos que indicam as ERB nos Mapa 2-7 apresentam uma capilarização importante, e, dependendo da área onde se implanta uma ERB, seu raio de cobertura pode variar de 100 metros a 150 quilômetros (Mobile Network Guide, [s.d.]).

As ERB se distribuem em redes herdadas, conforme as condições topológicas, na expectativa de retorno dos investimentos nessa infraestrutura pelos serviços prestados. A configuração territorial, então, parte da totalidade material de um compartimento do espaço geográfico com o conjunto de técnicas arranjadas em sistema que forma a configuração territorial.

A distribuição das ERB coincide com a interligação da rede backbone de fibra ótica, que começa com a internet via Embratel, em 1999, interligando, por meio de conexão de 155 Mbps, os principais centros de roteamento como Rio de Janeiro, Belo Horizonte, Brasília, Salvador, Campinas, Curitiba, São Paulo, Florianópolis e Porto Alegre.

Os investimentos nesse tipo de infraestrutura obedeceram a os interesses corporativos no processo de integração de redes para atender a demandas de variados serviços que têm agora como base sua organização na internet e na informação digital.

A distribuição e densidade das ERB segundo redes legadas e interesses corporativos para o uso do smartphone insere o indivíduo num circuito que envolve agentes hegemônicos como as operadoras de telecomunicação e o Estado, responsáveis por decisões sobre a localização e a regulação de torres e antenas, sem as quais é impossível conectar a internet.

Entender a ação desses agentes e sua regulação sobre esse serviço é conhecer o poder de controlar o uso de determinados territórios, reconfigurando usos já existentes ou criando novos. Há, portanto, uma estreita ligação entre as operadoras e o Estado e entre as decisões de localização e regulamentação.

As características do meio construídos herdado, as possibilidades de mercado e os interesses das empresas e do Estado constituem, juntamente com os atributos físicos do terreno, uma sobreposição entre condições técnicas da localização e as condições políticas e econômicas que determinam a localização precisa das ERB, que se apoiam em torres de três modelos assentados diretamente no solo ou no topo de prédios, como as torres compactas de metal que ocupam uma área pequena em relação a sua altura (20 a 30 metros) e podem ser instaladas em ambientes urbanos densos para atingir um grande número de usuários. A torre de metal em treliça, com área maior e altura de 30 metros, é instalada em ambientes urbanos menos densos, zonas rurais ou próximas a rodovias, para atingir um pequeno número de usuários, e a treliça de metal roof top é instalada no topo de prédios dos centros urbanos, onde há grande demanda e 
pouca área disponível para assentar os modelos anteriores. A localização eficiente no espaço é essencial para o imbricado sistema técnico de telefonia celular, pois é a base de torres e antenas que dá suporte ao funcionamento satisfatório da conexão do smartphone.

Tanto quanto pelo aspecto técnico da localização das ERB, as empresas se interessam pelas frações do território com maior contingente populacional capaz de pagar pelos serviços de conexão: "para que as redes possam estender-se, é preciso uma primeira inversão em infraestrutura de comunicações, que para ser rentável requer mercados, os quais em geral se dão quando a rede já está criada" (Sánchez, 1991, p. 290).

A distribuição espacial das ERB nas unidades federativas e nos centros urbanos hierarquicamente mais importantes, medida por indicadores de teledensidade e de habitantes por torre/antena, permite constatar que o Norte é a região brasileira com a menor densidade informacional, reforçando, ao lado da raridade das demais redes técnicas, uma distribuição desigual e pouco acessível em dadas porções do território. Isso ocorre em virtude do processo histórico de uso e ocupação do território, bem como pela forma desigual da divisão territorial do trabalho, em que o meio construído herdado é a condição que define a reprodução concentrada, desigual e seletiva do meio técnico-científico-informacional, além do tamanho continental do país e da densidade populacional. Nas cidades, é evidente o importante papel dos sistemas técnicos na definição e caracterização da reestruturação urbana atual.

A rede móvel sempre exigiu uma organização de agentes nas escalas municipal, estadual, nacional e planetária para todos os objetos, principalmente no âmbito jurídico e técnico, com interações de formas diferentes nas escalas local até a mundial, e o smartphone é capaz de aglutinar esses eixos de modo interescalar.

\section{Considerações finais}

A popularização do smartphone promove uma transformação profunda e significativa no uso do território brasileiro, tornando-o mais racionalizado e corporativo para agentes hegemônicos políticos e econômicos, engendrando comportamentos e mudanças territoriais.

Ressalta-se que a integração do território, possibilitada pelos novos meios de comunicação, não atinge igualmente todos os pontos, mas há uma integração seletiva e uma conexão parcial do território.

Pelos dados sobre a capilarização do uso do smartphone em várias porções do território, a participação dos indivíduos nas redes técnicas significa que eles se relacionam, influenciam e são influenciados pela articulação das relações urbanas por intermédio do vetor informacional produzindo a contiguidade dessa rede.

A interação no território não é só vertical, de ordens dirigidas aos indivíduos partindo de empresas ou do Estado ou de interações entre agentes hegemônicos, o que caracteriza dinâmicas da hierarquia urbana tradicional. Essa interação se dá também entre agentes individuais, quando a informação banal altera o tipo de interação espacial e pode promover ou ser ela própria uma nova forma de influenciar comportamentos. 
Nesse contexto, o conceito de heterarquia urbana ajuda a entender as interações interescalares e a nova situação geográfica criada pelos smartphones, pois as resultantes espaciais nem sempre são necessariamente hierárquicas em toda a sua dimensão, "podendo ser também heterárquicas, com interações interdependentes em que existem outros nós, intervalos e redes na constituição e diferenciação das funções e papéis das cidades na rede urbana" (Catelan, 2013, p. 80). Logo, intensifica-se a universalização de padrões técnicos e a ampliação de conteúdos e acessos à rede internet, justificando a aquisição de smartphones para a conexão.

As intersecções entre várias escalas combinam estruturas hierárquicas e heterárquicas por meio de ações verticais, horizontais ou transversais que se sucedem nas cidades e na rede urbana, articulando-as nos níveis local, regional, nacional e internacional.

As interações espaciais em várias escalas são orientadas por agentes hegemônicos, e a heterarquia pode ser entendida como outra relação além da hierárquica. A heterarquia não está em oposição à hierarquia da rede urbana, mas a complementa (Dreifuss, 1996), dada a importância das cidades na rede urbana quanto aos fluxos informacionais e ao acesso à internet.

A intensificação das interações espaciais amplia e torna mais complexas as funções das cidades pequenas e médias, visto que as horizontalidades e verticalidades concretizam uma rede que tem interações nas escalas do lugar, da formação socioespacial e do mundo, para um conjunto de cidades em vários pontos conectados do território.

As cidades em rede podem estabelecer conexão com outras de mesma ou de diferentes hierarquias por meio das diferentes densidades, alcances e intensidades das redes serviço que permitem o acesso à internet.

As interações espaciais entre agentes que se articulam em mais de uma escala fornecem elementos para interpretar como o fluxo de informações na metrópole e em cidades menores é heterogêneo e articula o local e o global.

Segundo Santos (1988, p. 12), "o espaço deve ser considerado como um conjunto indissociável de objetos geográficos, objetos naturais e objetos sociais e, de outro lado, a vida que os anima, ou aquilo que lhes dá vida, isto é, o movimento", e a complementaridade entre as várias escalas revela a articulação entre os agentes envolvidos atualmente na capilarização da informação.

Para que esse processo se concretize no território, é necessário que a contiguidade espacial se efetive por meio das redes e da "heterogeneização do papel e das funções das cidades na rede urbana, na interconexão de escalas geográficas e na ampliação da mobilidade do capital" (Catelan, 2013, p. 137).

A heterarquia urbana permite entender as novas dinâmicas que estruturam a rede urbana atual no contexto das interações espaciais urbanas interescalares, em que "a informação, sobretudo a serviço das forças econômicas, hegemônicas e a serviço do Estado, é o grande regedor das ações que definem as novas realidades espaciais" (Santos, 1996, p. 193). Assim, a heterarquia ocorre quando o local e o regional estão articulados para a reprodução do capital, e, assim, as redes coexistem em múltiplas escalas. 


\section{Referências}

ANATEL. AGÊNCIA NACIONAL DE TELECOMUNICAÇÕES. Setor Regulado: Conecta Brasil, 2018. Disponível em: http://www.anatel.gov.br/setorregulado/component/content/article/2-uncategorised/428-conecta-brasil. Acesso em: 1 maio 2019.

ANTAS JR., R. M. Território e regulação - espaço geográfico: fonte material e não-formal do direito. São Paulo: Humanitas, 2005.

ATLAS BRASILEIRO DE TELECOMUNICAÇÕES: o mapeamento das redes de serviços de telecom no Brasil - 2014. São Paulo: Converge Comunicações/Teletime/lpsis, 2016. Disponível em: https://issuu.com/telaviva/docs/atlas2014_site_baix2. Acesso em: 19 jul. 2019.

CASTILLO, R. A. Sistemas orbitais e uso do território: integração eletrônica e conhecimento digital no território brasileiro. Tese (Doutorado em Geografia Humana) Faculdade de Filosofia, Letras e Ciências Humanas, Universidade de São Paulo, São Paulo, 1999.

CATELAN, M. J. Heterarquia urbana: interações espaciais interescalares e cidades médias. São Paulo: Cultura Acadêmica, 2013.

CHRISTALLER, W. Central Places in Southern Germany. New Jersey: Prentice-Hall, 1966.

COMITÊ GESTOR DA INTERNET. Pesquisa sobre o setor de provimento de serviços de internet no Brasil - TIC Provedores 2014. NIC.BR/ CETIC.BR, 2016. Disponível em: http://www.cgi.br/publicacao/pesquisa-sobre-o-setor-de-provimento-de-servicos-de-internet-no-brasil/. Acesso em: 11 maio 2019.

CORRÊA, L. R. Processos, formas e interações espaciais. Revista Brasileira de Geografia, Rio de Janeiro, v. 61, n. 1, p. 127-143, jan./jun. 2016.

CORRÊA, L. R. Trajetórias geográficas. 2a ed. Rio de Janeiro: Bertrand Brasil, 2001.

CORRÊA, L. R. Interações espaciais. In: CASTRO, I. E.; GOMES, P. C. C.; CORRÊA, R.

L. (Org.). Explorações geográficas. Rio de Janeiro: Bertrand Brasil, 1997.

DIAS, L. C. Os sentidos da rede: notas para discussão. In: DIAS, L. C.; SILVEIRA, R. L. L. (Org.). Redes, sociedade e território. Santa Cruz do Sul, RS: Ed. Unisc, 2005.

DORFMAN, A. As escalas do território e sua articulação: uma revisão. In: MESQUITA, Z.; BRANDÃO, C. R. (Org.). Territórios do cotidiano: uma introdução a novos olhares e experiências. Porto Alegre: Ed. Unisc, 1995.

DREIFUSS, R. A. Conferência: heterarquia político-estratégica e heterotopia tecnoprodutiva. Ensaios FEE, Porto Alegre, v. 17, n. 2, p. 22-33, 1996.

DUARTE, F; FREY, K. Redes urbanas. In: DUARTE, F; QUANDT, C.; SOUZA, Q. (Org.). O tempo das redes. São Paulo: Perspectiva, 2008. 
IBGE. INSTITUTO BRASILEIRO DE GEOGRAFIA E ESTATÍSTICA. Pesquisa Nacional por Amostra de Domicílios Contínua (PNAD). Acesso à internet e à televisão e posse de telefone móvel celular para uso pessoal. Coordenação de Trabalho e Rendimento. Rio de Janeiro: IBGE, 2016. Disponível em: http://biblioteca.ibge.gov.br/ visualizacao/livros/liv95753.pdf. Acesso em: 21 maio 2019.

JENKINS, $\mathrm{H}$. Confronting the challenges of participatory culture: media education for the 21st Century. Cambridge, MA/London: The MIT Press, 2006. Disponível em: http://www.newmedialiteracies.org/wp-content/uploads/pdfs/NMLWhitePaper.pdf. Acesso em: 20 maio 2019.

LATOUR, B. A esperança de Pandora: ensaios sobre a realidade dos estudos científicos. Bauru, SP: Edusc, 2001.

LÉVY, P. Cibercultura. Trad. Carlos Irineu da Costa. São Paulo: Editora 34, 2000.

MOBILE NETWORK GUIDE. Mobile industry news, Reviews and Guides. Disponível em: http://www.mobilenetworkguide.com. Acesso em: 12 maio 2019.

MURRAY, J. Hamlet no Holodeck: o futuro da narrativa no ciberespaço. Trad. Elissa Khoru Daher e Marcelo Fernandez Cuzziol. São Paulo: Itaú Cultural/Unesp, 2003.

RAFFESTIN, C. Marxismo y geografía política. In: GARCÍA BALLESTEROS, A. (Coord.).

Geografías y marxismo. Madrid: Ed. Universidad Complutense, 1985.

SÁNCHEZ, J.-E. Espacio, economía y sociedad. Madrid: Siglo Veintiuno, 1991.

SANTOS, M. A natureza do espaço: técnica e tempo, razão e emoção. 4a ed. São Paulo: Edusp, 2006

SANTOS, M. Por uma outra globalização: do pensamento único à consciência universal. Rio de Janeiro: Record, 2000.

SANTOS, M. A natureza do espaço: técnica e tempo, razão e emoção. São Paulo: Hucitec, 1996.

SANTOS, M. Técnica, espaço, tempo: globalização e meio técnico-científico informacional. São Paulo: Hucitec, 1994.

SANTOS, M. O meio técnico-científico e a urbanização no Brasil. Espaço \& Debates, n. 25, p. 58-62, 1988.

SODRÉ, M. A comunicação do grotesco: um ensaio sobre a cultura de massa no Brasil. 5a ed. Petrópolis, RJ: Vozes, 1976.

TELEBRASIL. ASSOCIAÇÃO BRASILEIRA DE TELECOMUNICAÇÕES. Mapas das ERBs Brasil. 2018. Disponível em: http://www.telebrasil.org.br/panorama-do- setor/ mapa-de-erbs-antenas. Acesso em: 16 maio 2019. 